\section{Light pollution: the possible consequences of excessive illumination on retina}

MA Contín, MM Benedetto,

ML Quinteros-Quintana and ME Guido

\begin{abstract}
Light is the visible part of the electromagnetic radiation within a range of $380-780 \mathrm{~nm}$; (400-700 on primates retina). In vertebrates, the retina is adapted to capturing light photons and transmitting this information to other structures in the central nervous system. In mammals, light acts directly on the retina to fulfill two important roles: (1) the visual function through rod and cone photoreceptor cells and (2) non-image forming tasks, such as the synchronization of circadian rhythms to a $24 \mathrm{~h}$ solar cycle, pineal melatonin suppression and pupil light reflexes. However, the excess of illumination may cause retinal degeneration or accelerate genetic retinal diseases. In the last century human society has increased its exposure to artificial illumination, producing changes in the Light/Dark cycle,
\end{abstract}

as well as in light wavelengths and intensities. Although, the consequences of unnatural illumination or light pollution have been underestimated by modern society in its way of life, light pollution may have a strong impact on people's health. The effects of artificial light sources could have direct consequences on retinal health. Constant exposure to different wavelengths and intensities of light promoted by light pollution may produce retinal degeneration as a consequence of photoreceptor or retinal pigment epithelium cells death. In this review we summarize the different mechanisms of retinal damage related to the light exposure, which generates light pollution.

Eye (2016) 30, 255-263; doi:10.1038/eye.2015.221; published online 6 November 2015

\section{Introduction}

Light is the most potent entraining agent of life on earth that synchronizes circadian rhythms to a $24 \mathrm{~h}$ solar Light:Dark (LD) cycle. In mammals, light is detected by rods and cones that mediate visual function, and by intrinsically photosensitive retinal ganglion cells, which primarily project to the suprachiasmatic nucleus in the hypothalamus to regulate circadian rhythms and pupillary light reflexes. ${ }^{1,2}$ However, as a consequence of modern life, the alteration of the LD cycle by exposure to artificial light, impacts on living organisms and causes a number of detrimental effects, namely, the disturbance of behavioral and metabolic rhythms, alteration in diverse light-regulated physiological and psychological functions, and an environmental degradation with a strong force of selection on biodiversity. ${ }^{3-5}$ Lighting may alter natural light regimes spatially, temporally, and spectrally and influences biological systems, particularly the distinction between light as a resource and as an information source. ${ }^{6}$ Today our homes, work places, and streets are brightly illuminated by artificial electric lights during the day and night. Urban developments such as baby lights, TVs, computers, streetlights, emergency lights, or any environmental alteration are called 'light pollution', which is widely spread across the world and in constant growth. ${ }^{7,8}$

When Thomas Alva Edison (1879) invented the first electric bulbs, the effects of light pollution were underestimated; human society has changed ever since and today people rarely experience total darkness; so we are continuously exposed to unnatural illumination. The lack of dark experience promoted by excessive exposure to different wavelengths and intensities of light may produce circadian dyssynchrony, and thus metabolic dysfunction. ${ }^{9-12}$ Although light pollution effects have been analyzed from the social and economic points of view, from the vision of human health they have only been studied in relation to circadian rhythms; ${ }^{13,14}$ but not in relation to direct retinal damage, even when unnatural illumination may have drastic
Centro de Investigaciones en Química Biológica de Córdoba, (CIQUIBIC, UNC-CONICET),

Departamento de Química Biológica, Facultad de Ciencias Químicas, Universidad Nacional de Córdoba, Córdoba, Argentina

Correspondence:

MA Contín, Universidad Nacional de Córdoba, Haya de la Torre y Medina Allende, Ciudad Universitaria, X5000HUA, Ciudad Universitaria, Córdoba 5000, Argentina. Tel: +54 351433 4171/168;

Fax: +54 3514334074 . E-mail: mcontin@fcq.unc. edu.ar

Received: 11 May 2015 Accepted in revised form: 29 September 2015 Published online: 6 November 2015 
consequences on vision, mainly on the retina and its physiology.

It is known that photoreceptor cells need light to activate the photopigment, initiating the molecular cascade called phototransduction. During the vision process, the light captured produces photoreceptor cell hyperpolarization and stop of neurotransmitter release; however, light in excess (high irradiance or long-time exposure) may cause eye injury when focused onto the retina. Although the eye has developed very precise mechanisms of light adaptation and has several protective mechanisms against certain kinds of light exposure, prolonged or intense exposure causes cell death of photoreceptor cells and the resulting retinal degeneration and blindness. Light pollution may affect the human vision promoting retinal degeneration or accelerating some genetic diseases, such as retinitis pigmentosa (RP) or age-related macular degeneration (AMD). ${ }^{15-18}$

\section{Mechanisms of light-induced damage}

Light is the visible part of electromagnetic radiation in the wavelength range of $380-780 \mathrm{~nm}$ (violet to red light), where short wavelengths carry more energy than long ones. In living organisms, the radiant energy of electromagnetic radiation is transferred to tissue and may produce injury through photothermal, photochemical, and photomechanical mechanisms. Briefly, photothermal damage occurs when the rate of light liberated is faster than thermal diffusion, promoting a rise of tissue temperature. The exposure time that produces this kind of damage is around 0.1 and $1.0 \mathrm{~s}^{19}$ A $10^{\circ} \mathrm{C}$ increase of temperature in the retina induces protein denaturalization resulting in thermal damage. Photomechanical damage occurs when light energy is deposited before mechanical relaxation can occur. ${ }^{20}$

\section{Photochemical damage of the retina}

In the retina, the injury promoted by photochemical damage is independent from photothermal and photomechanical ones. Light absorbed in a chromophore initiates chemical reactions that may result in the transfer of energy, protons, or electrons to other molecules, which may become chemically reactive, process known as 'oxidative stress' (see below). ${ }^{21}$ One of the main causes of oxidative stress in the retina is the exposure to unnatural ambient light, ${ }^{22}$ where the severity of photochemical damage is influenced by many factors such as exposure time, intensity (high, moderate, or low), distribution of the radiant energy over the visible spectrum, body temperature, circadian phase, animal age, and environmental conditions. Retinal light damage is more pronounced in dorsal superior retina than in other adjacent areas, and it can be divided into two classes: (1) damage produced by low irradiance levels of white light, mediated by the activation of rhodopsin in photoreceptor cells; it may take days or weeks and usually it is principally located in the photoreceptor cells, and (2) damage produced by exposure to high irradiance with an action spectrum peaking at short wavelength of white light, where injuries occur at the retinal pigment epithelium and in some photoreceptor cells. ${ }^{21,23-26}$ In addition, under certain conditions of exposure, light could have cumulative effects in the processes of retinal damage. In this sense, Noel et al demonstrated that, in rats, 5 min of light exposure do not produce any effect over the retina, but if this exposure time is repeated three or four times, within $1 \mathrm{~h}$ of dark interval, significant damage to the retina occurs. However, if the retina is allowed to recover for more than $1 \mathrm{~h}$ in the dark, it does not present significant changes. ${ }^{22}$ Ham et al reported in rats that two $1000 \mathrm{~s}$ exposures at $441.5 \mathrm{~nm}$ spaced $48 \mathrm{~h}$ apart produced a lesion at one-half of the $1000 \mathrm{~s}$ threshold power. Furthermore, four or more exposures at one-fourth threshold spaced $48 \mathrm{~h}$ apart did not produce a lesion. ${ }^{27}$ Sperling et al, in 1980, compared lesions from a single 120 min exposure with those of daily intermittent exposures, and found histological different patterns with damage in daily exposure. ${ }^{28}$ In Rhesus monkey, Griess et $a^{29}$ showed that after time intervals of light exposure, retinal sites were re-exposed to determine the split-dose threshold related to the single-dose threshold through the additivity effect, which depend on time between exposures; they observed that recovery of tissue could be fitted by a single exponential with a time constant of 4 days. ${ }^{29}$ After that, Organisciak et al showed in rats that intermittent light exposure causes greater visual cell damage than continuous light exposure (in same time and light source ${ }^{24}$ and in 2006, Dong et al showed in mice that photochemical retinal injury from cumulative effect is caused by free radicals generated by continuous light exposure. ${ }^{30}$ Altogether, these findings demonstrate that retinal damage by intermittent light exposure promotes an irreversible damage, may be by the conditions, or schedule, by which the light is administered.

Because human society has changed the illumination conditions, we can speculate that light pollution may have negative consequences in retinal health. The intermittent exposure to artificial light produced by shift work activity, the exposure to high irradiance of artificial light by inside sources or lack experience of darkness could cause cumulative effects of damaged mechanism promoting retinal damage or accelerating retinal diseases, mainly in older individuals where anti-oxidative stress mechanisms are less effective. 


\section{Induced photochemical damage as a model of genetic diseases}

In many human diseases such as AMD and RP, photoreceptor cells' death is the principal event of retinal degeneration and it is known that the excessive exposure to natural or unnatural light may accelerate many of these. ${ }^{31-33}$ As such, models of light-induced

photoreceptor cells' death have been widely used to clarify the mechanism of injury in AMD and RP. Among the advantages of light exposure models over genetic animal models are: (1) lead to faster photoreceptor cells' degeneration, 2) initiate cell death of large numbers of photoreceptor cells in a synchronized manner, as opposed to genetic models, where photoreceptor cells are at various stages of health or degeneration, and (3) produce selective photoreceptor cells' death. ${ }^{34}$

Different established methods of light exposure are widely used in different vertebrates (fish, frogs, rats, and mice), allowing researchers to study the biochemical mechanism of retinal degeneration. Although different species may share some features in the biochemical mechanism of death in light damage, they seem to develop specific systems for each type of animal, therefore, to reduce confusion and advance our understanding about damage mechanisms, the researchers must be cautious about differences between species. As mentioned above, the severity of retinal damage is graded with light condition, because of that; the different setups of exposure to produce damage differ in light quality, intensity, or duration. in general, experiments using rich-energy blue light involve very short exposure periods to generate retinal degeneration (in the range of minutes) and for broadband green- and white-light exposure, durations vary between hours and weeks. ${ }^{27,35-37}$ Due to this diversity, it is hard to compare results obtained from different setups; however, the use of different models of light damage has helped identify different pathways of photoreceptor cells' apoptosis induced by light ${ }^{38,39}$ and could be useful both in the study of RP or AMD and in the effect of light pollution in modern society.

A work on albino and pigmented lines of gnat $1^{-/-}$and wild-type mice in a mixed background of $129 \mathrm{sv}$ and balb/c exposed to white-light fluorescent (ultraviolet impermeable) described two apoptotic pathways: (1) bright light-dependent apoptosis of photoreceptor cells through a mechanism requiring activation of rhodopsin but not of the phototransduction mechanism, and (2) low-light-dependent photoreceptor cells' apoptosis by photopigment activation and subsequent downstream signal transduction. ${ }^{38}$ However, it is difficult to establish a threshold between high- and low-intensity damage because it may depend on the species and genetic alteration of the animal studied.

\section{Bright light retinal damage}

There are many works concerning bright light damage, but in all of them the exposure is dramatic, because the entire population of visual cells is affected in a very short time. According to Noell et al, there are two mechanisms of retinal damage: (a) 'blue-light' and (b) 'visual pigmentmediated process'. They demonstrated clearly that, certain conditions such as light above a definite intensity, initiates a series of reactions that require the activation of rhodopsin photopigment. ${ }^{40}$ In this sense, Williams et al, ${ }^{41}$ using albino rats exposed to light with six different interference filters of narrow band-pass, showed a non-uniform distribution of damage across the retina, and they found that these phenomena are a rhodopsinmediated mechanism (retinal photodamage peaking at $500 \mathrm{~nm}) .{ }^{41,42}$ By using a mouse model lacking measurable amounts of functional rhodopsin (rpe ${ }^{-/-}$mouse) Grimm et $a l^{27}$ showed that the exposure to light do not induce apoptosis, indicating that rhodopsin photopigment constitutes the major mediator of light-induced damage. ${ }^{43,44}$ Remé et al ${ }^{39}$ discussed photoreceptor cells' death by apoptosis in blue and bright light, including the role of rhodopsin and photochemically active bleaching product that inflicts cellular damage, ${ }^{39}$ Organisciack et $a l^{45}$ describes the impact of intense light on retinal degeneration in genetic animal models and the protective effects of exogenous antioxidants and neurotrophic factors, discussing the innate ability of the retina to resist retinal light damage and its circadian-dependent vulnerability, ${ }^{45}$ and Grimm et al ${ }^{46}$ describes the methods for short-term exposures to bright full-spectrum white light and by short exposures to high-energy monochromatic blue or green light. ${ }^{46,47}$ All of them agree with the short-term and dramatic mechanisms of entire retinal degeneration where outer segments are involved.

In morphological studies, Ham et al ${ }^{48}$ demonstrated that the action spectrum for retinal damage near-ultraviolet spectrum (405, 380, 350, and $320 \mathrm{~nm}$ wavelengths) produced irreparable damage to rod and cone photoreceptor cells showing that the retina was six times more sensitive to 350 and $325 \mathrm{~nm}$ than to blue light (441 nm). ${ }^{48}$ Later, Gorgels et a ${ }^{49}$ demonstrated that wavelengths in the range of 320 to $440 \mathrm{~nm}$ produced a different mechanism of retinal damage than in animals exposed to 470-550 nm range. Retinal damage increases more from visible to ultraviolet wavelengths, indicating that two morphologically distinct types of damages occur in rat retina. ${ }^{49}$ Compelling evidence indicates that shorter wavelength (non-visible light) may not involve photopigment processes. Among whole sunlight spectrum received by the eyes, different eye tissues absorb radiation of wavelengths before reaching the retina and it vary depending on the species, pigmentation 
and age of the animal. It is know that rodent's cornea is thinner and transmit to retina much shorter wavelengths light than human cornea, therefore absorb UV light, and this should be taken into account when drawing conclusions. ${ }^{50}$ However, in general, retinal damage models are done in the spectrum of visible light range.

Here, we discuss some aspects of retinal degeneration produced by bright light related to retinal oxidative stress and the involvement of retinal pigment epithelium via retinoid processing.

\section{Effects of oxidative stress}

Free radicals are atoms or groups of atoms with an odd (unpaired) number of electrons that can be formed when oxygen interacts with certain molecules. The higher energy levels of free radicals are used to split the bond in another molecule by electron or hydrogen exchange.

Together with hydrogen peroxide $\left(\mathrm{H}_{2} \mathrm{O}_{2}\right)$ or ${ }^{1} \mathrm{O}_{2}$, they are called 'reactive oxygen intermediates'. Some of the stimuli that increases the production of reactive oxygen intermediates include irradiation, aging, inflammation, raised partial pressure of $\mathrm{O}_{2}$, air pollutants $\left(\mathrm{O}_{3}\right.$ and $\left.\mathrm{NO}_{2}\right)$, cigarette smoke, and reperfusion injury (for details see Beatty et $a l^{51}$ ). Under noxious stimuli, these intermediates can attack other molecules as carbohydrates, membrane lipids, proteins, and nucleic acids promoting damage. ${ }^{52,53}$ All these mechanisms are propagated as an uncontrolled chain reaction leading the breakdown of membranous structures, and therefore an extensive damage. ${ }^{21,52,54}$ The retina is probably the tissue that contains the highest endogenous photosensitizers that can be excited by light and, as a consequence, it is highly sensitive to damage. ${ }^{21}$ The proximity to choroidal blood vessels in the outer retina favors photoreceptor cells and retinal pigment epithelium cells to be highly oxygenated and consequently more sensitive to oxygen imbalance and photochemical damage; ${ }^{.51,55}$ however, the retina has a system that protects cells and tissue(s) against oxidative stress, aging or deficient nutritional conditions. These mechanisms could fail and the pathologic symptoms of retinal degeneration begins. ${ }^{56}$

\section{Low-light retinal damage}

Despite the high number of papers published on retinal light damage, most of them evaluate the effects of brightlight exposure on retinal morphology and function. The process of retinal cell death produced by lowintensity light stress may be different and it has not been well-characterized yet. In this section, we summarize the information about the implications of low-light exposure on the retina of different species. Noell et al ${ }^{22}$ described for the first time the damaging effect of light studying rat retina. In this study, retinal damage was caused in free running rats by long exposure to relatively low-light levels and the authors describe a depression of electroretinogram responses and photoreceptor cells' death. ${ }^{22}$ Later, other works demonstrated almost the same effects in different low-light exposure models; for example, Shear et $a l^{57}$ showed that in albino rats the retinal stimulation in continuous low white light ( $\approx 750$ lux) causes a progressive deterioration of photoreceptor cells. Based on structural retinal observations, they found that irreversible damage occurs in retinal pigment epithelium and photoreceptor cells after $96 \mathrm{~h}$ of constant light illumination; however, in shorter periods, structural changes were reversible. ${ }^{57}$ Similarly, Rapp et al, ${ }^{58}$ reported that rats exposed to 50 lux for periods ranging from 1 to 4.5 days followed by $12 \mathrm{~h}$ in darkness showed progressive photoreceptor cells' death, while animals kept in constant light for longer times of exposure showed a reduction in the level of rhodopsin and an increase in electroretinogram b-wave threshold. ${ }^{58}$ Hayasaka et al ${ }^{59}$ evaluated the activity level of some lysosomal enzymes involved in the pathogenesis of retinal degeneration, such as acid phosphatase,

$\beta$-glucuronidase, and Cathepsin D and B, showing that the activity of enzymes continuously exposed to light was higher than controls kept in LD. ${ }^{59}$ Penn et al ${ }^{60}$ evaluated the consequences of continuous exposure to 80 lux for $48 \mathrm{~h}$ at different postnatal age of Sprague-Dawley albino rats. Under dark conditions, 5-week-old rats had $\sim 20 \%$ less rhodopsin than 10 and 15 weeks old, both of which had $\sim 7 \%$ less than 20 weeks old. However, in exposed retinas, younger rats ( 5 and 10 weeks old) maintained a net gain in the photopigment for longer times due to the ability of rods to regenerate rhodopsin better than older animals; implying a greater photoreceptor cells' viability. ${ }^{60}$ Moriya et al ${ }^{61}$ studied the temporal sequence of ultrastructural changes induced by low-light exposure (80 lux light) for various periods of illumination time. They showed a set of early signs of abnormality such as degradation of some disks membranes at the tips of photoreceptor outer segment, disaggregation and detachment of ribosomes, lighter matrices in swollen mitochondria, disappearance of the Golgi apparatus, and proliferation of autophagic bodies in the inner segments. The authors report that these ultrastructural changes suggest that the excessive bleaching of rhodopsin stressed the metabolic capacity of rod cells and death occurs because cells cannot maintain their anabolic balance. ${ }^{61}$

Recently, in our laboratory we have begun to evaluate the time course and molecular mechanisms of death in Wistar rats during continuous low intensity light exposure. We found that constant light, but not cyclic exposure to 200 lux for 7 days, produces apoptotic cell death of rods and does not alter rhodopsin expression 
before photoreceptor cells' death. ${ }^{35}$ However, the photopigment was more phosphorylated in $\operatorname{ser}^{334}$ than in control animals. Further investigation need to be carried out to know whether low-light damage could involve other mechanisms in parallel to phototransduction cascade. It is difficult to believe that in constant light other mechanisms such as oxidative stress and the resulting production of reactive oxygen species would not to be involved. ${ }^{35}$

\section{Brief review of circadian rhythms}

Circadian rhythms are biological oscillations within an approximate 24 -h period generated by a network of transcriptional and translational loops in the expression of so-called clock genes. ${ }^{2,62}$ Light is the main and strongest synchronizer of the circadian system, while the retina is responsible for sensing the environmental lighting conditions, which change throughout the LD cycles, in at least six orders of magnitude, to adjust endogenous clocks located in the brain. Brainard et al ${ }^{63}$ found that human melatonin levels were reduced most when volunteers were exposed to monochromatic blue light between 0200 and 0330 hours and proposed a novel mechanism of photoperception different from rod and cones. ${ }^{63,64}$ Today it is known that to fulfill these functions, the retina contains a subpopulation or intrinsically photosensitive retinal ganglion cells that express melanopsin photopigment and connect to the circadian or biological clock center within the hypothalamus, at the base of the brain. 1,62,65,66 These cells present a different phototransduction mechanism from rod and cone cells, involving the activation of phospholipase $C$ and calcium mobilization and membrane depolarization. ${ }^{1,67-71}$

Melatonin is a protective, oncostatic hormone, and strong antioxidant having evolved in all plants and animals that present circadian phase. In vertebrates, melatonin is normally produced by the pineal gland during the early morning hours of darkness, and is regulated by LD cycles. ${ }^{72}$ The exposures to visible wavelengths of light at night produce suppression of normal nocturnal production of melatonin by the pineal gland. ${ }^{64,73-75}$ It has consequences in the human physiology and could have drastically negative effects on human health, such as an increase in psychological distress levels ${ }^{76}$ and development of cancer. ${ }^{77}$ In this respect, there are indirect studies related to the exposure of shift workers to light at night, which have higher incidences of breast and colorectal cancer where one possible cause is melatonin suppression by eyes exposure to light. $8,78-80,81$ Light pollution promoted by artificial light in modern life has facilitated changes in the temporal architecture of human lifestyle tending to do activities such as sleeping, eating, and doing exercise at inappropriate times. All these changes in the activities produce chronic circadian desynchrony and may affect health and lifespan as metabolic and behavioral phenotype that may predisposed to obesity. ${ }^{82}$ In many cases organisms have been shown to be sensitive to extremely low levels of light at night, well within levels of anthropogenic light pollution. ${ }^{83,84}$ The unnatural illumination in light pollution could specifically produce damage in the intrinsically photosensitive retinal ganglion cells by constant illumination or resynchronization in normal LD cycle, therefore, the lack of information input by inner retina could add to the phenomenon of circadian desynchrony.

In retina, it is thought that melatonin acts locally as a nocturnal signaling molecule that regulates its physiology on a temporal basis. ${ }^{85-88}$ Rhythms in this hormone persist in isolated retinas or dissociated cells and remain visible for a number of days in culture. ${ }^{89-92}$ Melatonin is mainly synthesized in the photoreceptor cells with higher levels at night; ${ }^{89}$ however, it has been shown that the inner retina of some vertebrates has the ability to synthesize it as well; moreover, in some fish species, it is also produced during the day. ${ }^{93}$

\section{Unnatural light sources}

As we mention in this review, in the last years, the human society expanded the unnatural illumination using different kind of light sources. These artificial illuminations changed our way of life altering the natural LD cycle and therefore desynchronizing the biological rhythms, and inducing behaviors of longer time of light exposition with possible consequences in retinal health.

In the beginning of use of artificial illumination, the light sources were compact fluorescent or incandescent lamps. Most of the works' comments in this review have been focused on light exposure models as white fluorescent lamp or different wavelength or intensity light allowing demonstrate the consequences in retina health. In the last years; in order to protect the environment, it was necessary to improve the energy performance of domestic use of light. For this reason, the compact fluorescent lamp is being replaced by light-emitting diodes (LED), although the potential risk of retinal damage that this kind of light entails, must be evaluated (see Behar-Cohen et $a l^{20}$ and Behar-Cohen ${ }^{94}$ ). LEDs products emit blue light (wavelengths of 460-500 nm) and, as mentioned above, blue-light exposure has a powerful role on retinal degeneration. In our retinal damage model, when we exposed wistar rats to constant white light with LED sources at 200 lux, the photoreceptor cells die after 5 days. The mechanism of cell death could be attributed to constant activation of phototransduction without discarding oxidative stress mechanism. ${ }^{35}$ In studies at higher intensity exposure (3 h of LED at 5000 lux), Sprague-Dawley rats showed a 


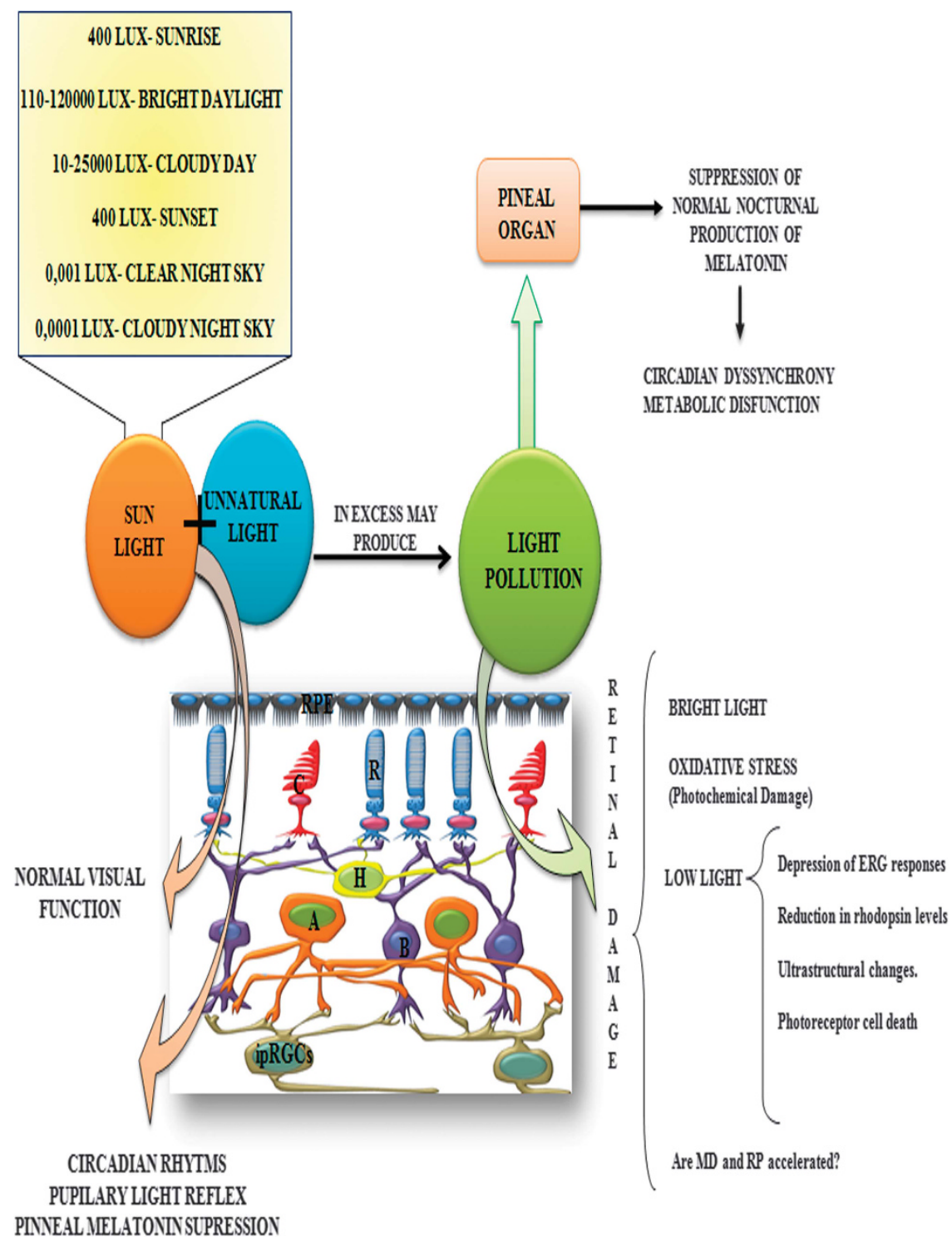

Figure 1 Effect of Light Pollution on retina. Photoreceptor cells, retinal pigment epithelium, and intrinsically photosensitive retinal ganglion cells could be affected by high or prolonged low-light exposure, promoted by light during the night or indoor artificial illumination with high irradiance. These events may affect the general retinal physiology or accelerate some genetic diseases ending in blindness. These phenomena called light pollution is promoted by the customs of modern life where the human society had changed the natural circadian ld cycle. Furthermore, as a consequence of photoreceptor cells' death (cone, rod, and intrinsically photosensitive retinal ganglion cells); light pollution could have effects on the pineal organ, producing desynchronization of the circadian system, malfunctions in pupillary light reflex, and metabolic dysfunctions endangering human health. R, rods; C, cones; H, horizontal; B, bipolar; A, amacrine; ipRGCs, intrinsically photosensitive retinal ganglion cells; RPE, retinal pigment epithelium.

significant reduction of electroretinogram b-wave amplitudes and mean outer nuclear layer thicknesses; however, previous injections of hydrogen-rich saline solution showed protection against these light-induced retinal degeneration. ${ }^{95}$ Recently, Chamorro et al demonstrated that human retinal pigment epithelium, exposed to three LD $(12: 12 \mathrm{~h})$ cycles, using LED at blue- $468 \mathrm{~nm}$, green- $525 \mathrm{~nm}$, red- $616 \mathrm{~nm}$, and white light, decrease $75-99 \%$ cellular viability, and increase $66-89 \%$ cellular apoptosis. They also demonstrated an increasing of reactive oxygen species production and DNA damage indicating that three LD $(12: 12 \mathrm{~h})$ cycles of exposure to LED lighting affect in vitro human retinal pigment epithelium. After that, Shang et al ${ }^{37}$ demonstrated apoptosis and necrosis of photoreceptor cells and free radical production in the retina in SpragueDawley rats exposed to blue LEDs $(460 \mathrm{~nm})$ or fullspectrum white LEDs. ${ }^{37}$ Again, light exposure models on different rats, time exposure, and intensity can yield different results and is hardly possible to compare 
results obtained from different setups. However, the fact that LED technology produces retinal damage in all the intensities and wavelengths studied must be taken into account when deciding what kind of artificial illumination to use.

\section{Conclusions}

The consequences of permanent light exposure are still unknown and even analyzing all knowledge in retinal light damage, we cannot rule out the risk of a chronic (intermittent or not) or high exposure to light promoted by light pollution on visual system. Cones, rods, retinal pigment epithelium, and intrinsically photosensitive retinal ganglion cells could be affected by high or prolonged light exposure induced by habits of modern life (Figure 1). Cumulative effects, long exposure by absence of profound experiences of dark during the night and high irradiance exposure by LED technology may affect the retinal physiology promoting cell death and the consequent blindness and desynchrony.

The background knowledge about high- or low-light retinal damage in different animal models, allow us to speculate the potential damage that this kind of luminance could cause in the human retinal health. Light pollution may increment or accelerate oxidation mechanisms in which antioxidants defenses cannot revert these processes and the simple exposure during different periods to unnatural illumination during dark could produce retinal damage. In addition, light pollution could be a trigger for inherited diseases such as AMD and RP, promoting early onset of symptoms or accelerating the retinal degeneration processes. Furthermore, due to photoreceptor cells' death (cone, rod, and intrinsically photosensitive retinal ganglion cells), unnatural illumination could add effects of desynchronization of the circadian system or cause malfunctions in pupillary light reflex or other non-imaging forming tasks.

Future research focused on the study of the use of LED technology should be considered. The intensities, duration, and spectrum of wavelength light that are using as artificial sources should be taken into account in future research. The information retrievable on in vitro and in vivo models in different animals will be useful for the knowledge of retinal degeneration mechanisms, and for discovery of drugs that can prevent or revert these processes. However, at time to compare the knowledge, we must not lose sight of the differences in the eye anatomy between species. Several strategies could be used to minimize it and address experimental condition that may not be performed in primates by the system complexity. For example, the use of filters that do not let pass wavelength absorbed by rodent cornea to simulate the primate cornea; or the use of total retina of rat (without macula and low cones) to study the rod photoreceptors cell death, could be useful to non-primate animal models and therefore resemble primates.

Maybe, by ecological advantages, it is difficult to reduce the use of LED, so the application of appropriate filters may prevent the intensities of blue light; decreasing upon arrival to the eye, improving the lighting system, and decreasing the risk of retinal degeneration.

Basic research can help about this regard.

\section{Conflict of interest}

The authors declare no conflict of interest.

\section{Acknowledgements}

We are grateful to Gabriela DiazCortez for doing the language quality check of this manuscript. This work has been supported by Agencia Nacional de Promoción Científica y Técnica (FONCyT, PICT 2012 No 0364, PICT 2010 No 647), Consejo Nacional de Investigaciones Científicas y Tecnológicas de la República Argentina (CONICET), Secretaría de Ciencia y Tecnología de la Universidad Nacional de Córdoba (SeCyT-UNC), and Ministerio de Ciencia y Tecnología de Córdoba.

\section{References}

1 Berson DM, Dunn FA, Takao M. Phototransduction by retinal ganglion cells that set the circadian clock. Science 2002; 295: 1070-1073.

2 Guido ME, Garbarino-Pico E, Contin M, Valdez DJ, Nieto PS, Verra DM et al. Inner retinal circadian clocks and nonvisual photoreceptors: novel players in the circadian system. Prog Neurobiol 2010; 92: 484-504.

3 Grimm NB, Faeth SH, Golubiewski NE, Redman CL, Wu J, Bai $X$ et al. Global change and the ecology of cities. Science 2008; 319: 756-760.

4 Navara KJ, Nelson RJ. The dark side of light at night: physiological, epidemiological, and ecological consequences. J Pineal Res 2007; 43: 215-224.

5 Shuboni D, Yan L. Nighttime dim light exposure alters the responses of the circadian system. Neuroscience 2010; 170: $1172-1178$.

6 Gaston KJ, Bennie J, Davies TW, Hopkins J. The ecological impacts of nighttime light pollution: a mechanistic appraisal. Biol Rev Camb Philos Soc 2013; 88: 912-927.

7 Kantermann T, Roenneberg T. Is light-at-night a health risk factor or a health risk predictor? Chronobiol Int 2009; 26: 1069-1074.

8 Pauley SM. Lighting for the human circadian clock: recent research indicates that lighting has become a public health issue. Med Hypotheses 2004; 63: 588-596.

9 Bedrosian TA, Fonken LK, Walton JC, Nelson RJ. Chronic exposure to dim light at night suppresses immune responses in Siberian hamsters. Biol Lett 2011; 7: 468-471.

10 Fonken LK, Aubrecht TG, Melendez-Fernandez OH, Weil ZM, Nelson RJ. Dim light at night disrupts molecular circadian rhythms and increases body weight. J Biol Rhythms 2013; 28: 262-271. 
11 Fonken LK, Weil ZM, Nelson RJ. Mice exposed to dim light at night exaggerate inflammatory responses to lipopolysaccharide. Brain Behav Immun 2013; 34: 159-163.

12 Holzman DC. What's in a color? The unique human health effect of blue light. Environ Health Perspect 2010; 118: A22-A27.

13 Chalkias C, Petrakis M, Psiloglou B, Lianou M. Modelling of light pollution in suburban areas using remotely sensed imagery and GIS. J Environ Manage 2006; 79: 57-63.

14 Solano Lamphar HA, Kocifaj M. Light pollution in ultraviolet and visible spectrum: effect on different visual perceptions. PLoS One 2013; 8: e56563.

15 Walls HL, Walls KL, Benke G. Eye disease resulting from increased use of fluorescent lighting as a climate change mitigation strategy. Am J Public Health 2011; 101: 2222-2225.

16 Marquioni-Ramella MD, Suburo AM. Photo-damage, photoprotection and age-related macular degeneration. Photochem Photobiol Sci 2015; 14: 1560-1577.

17 Taylor HR, West S, Muñoz B, SB Rosenthal FSBressler, Bressler NM. The long-term effects of visible light on the eye. Arch Ophthalmol 1992; 110: 99-104.

18 Nowak JZ. AMD—the retinal disease with an unprecised etiopathogenesis: in search of effective therapeutics. Acta Pol Pharm 2014; 71: 900-916.

19 Crochet JJ, Gnyawali SC, Chen Y, Lemley EC, Wang LV, Chen WR. Temperature distribution in selective laser-tissue interaction. J Biomed Opt 2006; 11: 34031.

20 Behar-Cohen F, Martinsons C, Viénot F, Zissis G, Barlier-Salsi A, Cesarini JP et al. Light-emitting diodes (LED) for domestic lighting: any risks for the eye? Prog Retin Eye Res 2011; 30: 239-257.

$21 \mathrm{Wu}$ J, Seregard S, Algvere PV. Photochemical damage of the retina. Surv Ophthalmol 2006; 51: 461-481.

22 Noell WK, Walker VS, Kang BS, Berman S. Retinal damage by light in rats. Invest Ophthalmol 1966; 5: 450-473.

23 Grimm C, Wenzel A, Williams T, Rol P, Hafezi F, Remé C et al. Rhodopsin-mediated blue-light damage to the rat retina: effect of photoreversal of bleaching. Invest Ophthalmol Vis Sci 2001; 42: 497-505.

24 Organisciak DT, Jiang YL, Wang HM, Pickford M, Blanks JC. Retinal light damage in rats exposed to intermittent light. Comparison with continuous light exposure. Invest Ophthalmol Vis Sci 1989; 30: 795-805.

25 Organisciak DT, Wang HM, Xie A, Reeves DS, Donoso LA Intense-light mediated changes in rat rod outer segment lipids and proteins. Prog Clin Biol Res 1989; 314: 493-512.

26 Rozanowska M, Sarna T. Light-induced damage to the retina: role of rhodopsin chromophore revisited. Photochem Photobiol 2005; 81: 1305-1330.

27 Ham Jr WT, Mueller HA, Ruffolo Jr JJ, Clarke AM. Sensitivity of the retina to radiation damage as a function of wavelength. Photochem Photobiol 1979; 29: 735-743.

28 Sperling HG, Johnson C, Harwerth RS. Differential spectral photic damage to primate cones. Vision Res 1980; 20: 1117-1125.

29 Griess GA, Blankenstein MF. Additivity and repair of actinic retinal lesions. Invest Ophthalmol Vis Sci 1981; 20: 803-807.

30 Dong A, Shen J, Krause M, Akiyama H, Hackett SF, Lai H et al. Superoxide dismutase 1 protects retinal cells from oxidative damage. J Cell Physiol 2006; 208: 516-526.

31 Paskowitz DM, LaVail MM, Duncan JL. Light and inherited retinal degeneration. Br J Ophthalmol 2006; 90: 1060-1066.

32 Portera-Cailliau C, Sung CH, Nathans J, Adler R. Apoptotic photoreceptor cell death in mouse models of retinitis pigmentosa. Proc Natl Acad Sci USA 1994; 91: 974-978.
33 Reme CE, Grimm C, Hafezi F, Marti A, Wenzel A. Apoptotic cell death in retinal degenerations. Prog Retin Eye Res 1998; 17: 443-464.

34 Wenzel A, Grimm C, Samardzija M, Reme CE. Molecular mechanisms of light-induced photoreceptor apoptosis and neuroprotection for retinal degeneration. Prog Retin Eye Res 2005; 24: 275-306.

35 Contin MA, Arietti MM, Benedetto MM, Bussi C, Guido ME. Photoreceptor damage induced by low-intensity light: model of retinal degeneration in mammals. Mol Vis 2013; 19: 1614-1625.

36 Hafezi F, Marti A, Munz K, Reme CE. Light-induced apoptosis: differential timing in the retina and pigment epithelium. Exp Eye Res 1997; 64: 963-970.

37 Shang YM, Wang GS, Sliney D, Yang CH, Lee LL. White Light-Emitting Diodes (LEDs) at Domestic Lighting Levels and Retinal Injury in a Rat Model. Environ Health Perspect 2014; 122: 269-276.

38 Hao W, Wenzel A, Obin MS, Chen CK, Brill E, Krasnoperova NV et al. Evidence for two apoptotic pathways in light-induced retinal degeneration. Nat Genet 2002; 32: 254-260.

39 Reme CE. The dark side of light: rhodopsin and the silent death of vision the proctor lecture. Invest Ophthalmol Vis Sci 2005; 46: 2671-2682.

40 Noell WK. Possible mechanisms of photoreceptor damage by light in mammalian eyes. Vision Res 1980; 20: 1163-1171.

41 Williams TD. Speculations on the direction of the optic nerve. Am J Optom Physiol Opt 1983; 60: 303-307.

42 Williams TP, Webbers JP. Photometer for measuring intensity and rhodopsin distributions in intact eyes. Appl Opt 1995; 34: 5720-5724.

43 Grimm C, Wenzel A, Hafezi F, Yu S, Redmond TM, Remé CE et al. Protection of Rpe65-deficient mice identifies rhodopsin as a mediator of light-induced retinal degeneration. Nat Genet 2000; 25: 63-66.

44 Wenzel A, Reme CE, Williams TP, Hafezi F, Grimm C. The Rpe65 Leu450Met variation increases retinal resistance against light-induced degeneration by slowing rhodopsin regeneration. J Neurosci 2001; 21: 53-58.

45 Organisciak DT, Vaughan DK. Retinal light damage: mechanisms and protection. Prog Retin Eye Res 2010; 29: 113-134.

46 Grimm C, Reme CE. Light damage as a model of retinal degeneration. Methods Mol Biol 2013; 935: 87-97.

47 Grimm C, Reme CE, Rol PO, Williams TP. Blue light's effects on rhodopsin: photoreversal of bleaching in living rat eyes. Invest Ophthalmol Vis Sci 2000; 41: 3984-3990.

48 Ham Jr WT, Mueller HA, Ruffolo Jr JJ, Guerry 3rd D, Guerry RK. Action spectrum for retinal injury from near-ultraviolet radiation in the aphakic monkey. Am J Ophthalmol 1982; 93: 299-306.

49 Gorgels TG, van Norren D. Ultraviolet and green light cause different types of damage in rat retina. Invest Ophthalmol Vis Sci 1995; 36: 851-863.

50 Dillon J, Zheng L, Merriam JC, Gaillard ER. Transmission spectra of light to the mammalian retina. Photochem Photobiol 2000; 71: 225-229.

51 Beatty S, Koh H, Phil M, Henson D, Boulton M. The role of oxidative stress in the pathogenesis of age-related macular degeneration. Surv Ophthalmol 2000; 45: 115-134.

52 Demontis GC, Longoni B, Marchiafava PL. Molecular steps involved in light-induced oxidative damage to retinal rods. Invest Ophthalmol Vis Sci 2002; 43: 2421-2427.

53 Heil K, Pearson D, Carell T. Chemical investigation of light induced DNA bipyrimidine damage and repair. Chem Soc Rev 2011; 40: 4271-4278. 
54 Youssef PN, Sheibani N, Albert DM. Retinal light toxicity. Eye (Lond) 2011; 25: 1-14.

55 Yu DY, Cringle SJ. Retinal degeneration and local oxygen metabolism. Exp Eye Res 2005; 80: 745-751.

56 Siu TL, Morley JW, Coroneo MT. Toxicology of the retina: advances in understanding the defence mechanisms and pathogenesis of drug- and light-induced retinopathy. Clin Experiment Ophthalmol 2008; 36: 176-185.

57 Shear CR, O'Steen WK, Anderson KV. Effects of short-term low intensity light on the albino rat retina. An electron microscopic study. Am J Anat 1973; 138: 127-132.

58 Rapp LM, Williams TP. Damage to the albino rat retina produced by low intensity light. Photochem Photobiol 1979; 29 731-733.

59 Hayasaka S, Lai YL. Effect of continuous low-intensity light on the lysosomal enzymes in the retina of albino rats. Exp Eye Res 1979; 29: 123-129.

60 Penn JS, Baker BN, Howard AG, Williams TP. Retinal lightdamage in albino rats: lysosomal enzymes, rhodopsin, and age. Exp Eye Res 1985; 41: 275-284.

61 Moriya M, Baker BN, Williams TP. Progression and reversibility of early light-induced alterations in rat retinal rods. Cell Tissue Res 1986; 246: 607-621.

62 Peirson S, Foster RG. Melanopsin: another way of signaling light. Neuron 2006; 49: 331-339.

63 Brainard GC, Hanifin JP, Greeson JM, Byrne B, Glickman G, Gerner $\mathrm{E}$ et al. Action spectrum for melatonin regulation in humans: evidence for a novel circadian photoreceptor. J Neurosci 2001; 21: 6405-6412.

64 Brainard GC, Hanifin JP, Rollag MD, Greeson J, Byrne B, Glickman $\mathrm{G}$ et al. Human melatonin regulation is not mediated by the three cone photopic visual system. J Clin Endocrinol Metab 2001; 86: 433-436.

65 Berson DM. Strange vision: ganglion cells as circadian photoreceptors. Trends Neurosci 2003; 26: 314-320.

66 Hattar S, Lucas RJ, Mrosovsky N, Thompson S, Douglas RH et al. Melanopsin and rod-cone photoreceptive systems account for all major accessory visual functions in mice. Nature 2003; 424: 76-81.

67 Berson DM. Phototransduction in ganglion-cell photoreceptors. Pflugers Arch 2007; 454: 849-855.

68 Contin MA, Verra DM, Guido ME. An invertebratelike phototransduction cascade mediates light detection in the chicken retinal ganglion cells. Faseb J 2006; 20: 2648-2650.

69 Contin MA, Verra DM, Salvador G, Ilincheta M, Giusto NM, Guido ME. Light-activation of the Phosphoinositide Cycle in Intrinsically Photosensitive Chicken Retinal Ganglion Cells. Invest Ophthalmol Vis Sci 2010; 51: 5491-5498.

70 Panda S, Nayak SK, Campo B, Walker JR, Hogenesch JB, Jegla T. Illumination of the melanopsin signaling pathway. Science 2005; 307: 600-604.

71 Sekaran S, Lupi D, Jones SL, Sheely CJ, Hattar S, Yau KW et al. Melanopsin-dependent photoreception provides earliest light detection in the mammalian retina. Curr Biol 2005; 15: 1099-1107.

72 Brainard GC, Rollag MD, Hanifin JP. Photic regulation of melatonin in humans: ocular and neural signal transduction. J Biol Rhythms 1997; 12: 537-546.

73 Rea MS, Bullough JD, Figueiro MG. Phototransduction for human melatonin suppression. J Pineal Res 2002; 32: 209-213.

74 Thapan K, Arendt J, Skene DJ. An action spectrum for melatonin suppression: evidence for a novel non-rod, non-cone photoreceptor system in humans. J Physiol 2001; 535: 261-267.
75 Zeitzer JM, Ayas NT, Shea SA, Brown R, Czeisler CA. Absence of detectable melatonin and preservation of cortisol and thyrotropin rhythms in tetraplegia. J Clin Endocrinol Metab 2000; 85: 2189-2196.

76 Shields M. Shift work and health. Health Rep 2002; 13: 11-33.

77 Ben-Shlomo R. Chronodisruption, cell cycle checkpoints and DNA repair. Indian J Exp Biol 2014; 52: 399-403.

78 Blask DE, Dauchy RT, Sauer LA, Krause JA, Brainard GC. Light during darkness, melatonin suppression and cancer progression. Neuro Endocrinol Lett 2002; 23(Suppl 2): 52-56.

79 Davis S, Mirick DK, Stevens RG. Night shift work, light at night, and risk of breast cancer. J Natl Cancer Inst 2001; 93: 1557-1562.

80 Schernhammer ES, Laden F, Speizer FE, Willett WC, Hunter DJ, Kawachi I et al. Night-shift work and risk of colorectal cancer in the nurses' health study. J Natl Cancer Inst 2003; 95: 825-828.

81 Bauer SE, Wagner SE, Burch J, Bayakly R, Vena JE. A case-referent study: light at night and breast cancer risk in Georgia. Int J Health Geogr 2013; 12: 23.

82 Wyse CA, Selman C, Page MM, Coogan AN, Hazlerigg DG Circadian desynchrony and metabolic dysfunction; did light pollution make us fat? Med Hypotheses 2011; 77: 1139-1144.

83 Kelber A, Roth LS. Nocturnal colour vision-not as rare as we might think. J Exp Biol 2006; 209: 781-788.

84 Bachleitner W, Kempinger L, Wulbeck C, Rieger D, HelfrichForster C. Moonlight shifts the endogenous clock of Drosophila melanogaster. Proc Natl Acad Sci USA 2007; 104: 3538-3543.

85 Iuvone PM, Tosini G, Pozdeyev N, Haque R, Klein DC, Chaurasia SS. Circadian clocks, clock networks, arylalkylamine $\mathrm{N}$-acetyltransferase, and melatonin in the retina. Prog Retin Eye Res 2005; 24: 433-456.

86 Tosini G. Melatonin circadian rhythm in the retina of mammals. Chronobiol Int 2000; 17: 599-612.

87 Tosini G, Dirden JC. Dopamine inhibits melatonin release in the mammalian retina: in vitro evidence. Neurosci Lett 2000; 286: 119-122.

88 Tosini G, Menaker M. The clock in the mouse retina: melatonin synthesis and photoreceptor degeneration. Brain Res 1998; 789: 221-228.

89 Cahill GM, Besharse JC. Circadian clock functions localized in xenopus retinal photoreceptors. Neuron 1993; 10: 573-577.

90 Iuvone PM. Development of melatonin synthesis in chicken retina: regulation of serotonin $\mathrm{N}$-acetyltransferase activity by light, circadian oscillators, and cyclic AMP. J Neurochem 1990; 54: 1562-1568.

91 Tosini G, Menaker M. The pineal complex and melatonin affect the expression of the daily rhythm of behavioral thermoregulation in the green iguana. J Comp Physiol A 1996; 179: 135-142.

92 Besharse JC, Iuvone PM. Circadian clock in Xenopus eye controlling retinal serotonin $\mathrm{N}$-acetyltransferase. Nature 1983; 305: 133-135.

93 Falcon J. [Photoreceptor cells, circadian oscillators and control of the rhythmic production of melatonin. Perspectives]. Pathol Biol (Paris) 1993; 41: 919-922.

94 Behar-Cohen F. [Retinal drug targets]. Ann Pharm Fr 2011; 69: 124-130.

95 Tian L, Zhang L, Xia F, An J, Sugita Y, Zhang Z. Hydrogenrich saline ameliorates the retina against light-induced damage in rats. Med Gas Res 2013; 3: 19. 